\author{
Alexandra Ros ${ }^{1}$ \\ Michel Faupel $^{2}$ \\ Hervé Mees ${ }^{2}$ \\ Jan van Oostrum ${ }^{2}$ \\ Rosaria Ferrigno ${ }^{1}$ \\ Frédéric Reymond ${ }^{3}$ \\ Philippe Michel $^{3}$ \\ Joël S. Rossier ${ }^{1}$ \\ Hubert H. Girault ${ }^{1}$ \\ ${ }^{1}$ Laboratoire d'Electrochimie, \\ Département de Chimie, \\ Ecole Polytechnique \\ Fédérale de Lausanne, \\ Lausanne, Switzerland \\ ${ }^{2}$ Functional Genomics Area, \\ Novartis Pharma, \\ Basel, Switzerland \\ ${ }^{3}$ DiagnoSwiss, \\ Monthey, Switzerland
}

\section{Protein purification by Off-Gel electrophoresis}

A novel free-flow protein purification technique based on isoelectric electrophoresis is presented, where the proteins are purified in solution without the need of carrier ampholytes. The gist of the method is to flow protein solutions under an immobilised $\mathrm{pH}$ gradient gel (IPG) through which an electric field is applied perpendicular to the direction of the flow. Due to the buffering capacity of the IPG gel, proteins with an isoelectric point $(\mathrm{p} /)$ close to $\mathrm{pH}$ of the gel in contact with the flow chamber stay in solution because they are neutral and therefore not extracted by the electric field. Other proteins will be charged when approaching the IPG gel and are extracted into the gel by the electric field. Both a demonstration experiment with $\mathrm{p} /$ markers and a simulation of the electric field distribution are presented to highlight the principle of the system. In addition, an isoelectric fractionation of an Escherichia coli extract is shown to illustrate the possible applications.

Keywords: Isoelectric focusing / Prefractionation / Isoelectric purification

\section{Introduction}

Fast protein analysis is becoming a key issue in the challenge of modern biology. Proteomics methods rely heavily on 2-D gel electrophoresis to identify and classify proteins according to their isoelectric point and mass [1, 2]. This classification has enabled the creation of protein databases of expressed proteins [3]. Subsequent analyses of the proteins such as sequencing, biological activity or structure determination require an extraction procedure from the gel, for example either by blotting or by spot cutting. Complementary approaches to 2-D gel electrophoresis rely on the development of microarrays, e.g. for the study of protein-protein interactions [4] combined with a mass spectrometric determination of the proteins complexes. For these proteomic methodologies, efficient upstream purification or prefractionation steps can seriously decrease the complexity of a biological matrix. For example, it has been recently described by Righetti et al. [5] that after prefractionation of an Escherichia coli extract, many more spots were observed on a 2-D analysis map compared to standard maps. At this stage, chromatographic techniques such as ion chromatography, microfluidic based isoelectric focusing [6] or dialysis have also been shown to prepare a sample prior to 2-D or 1-D gel electrophoresis. Classically, two major isoelec-

Correspondence: Professor Hubert H. Girault, Laboratoire d'Electrochimie Départment de Chimie, Ecole Polytechnique Fédérale de Lausanne, $\mathrm{CH}-105$ Lausanne, Switzerland

E-mail: hubert.girault@epfl.ch

Fax: +41216933667 tric focusing systems are used in sample preparation: (i) free flowing buffered systems, and (ii) immobilized buffered systems.

All free flowing systems use a buffer, mainly carrier ampholytes or isoelectric buffers such as amino acids in order to fix the $\mathrm{pH}$. On this principle numerous applications have been shown over the last 30 years with free flow electrophoresis. In particular, Weber et al. developed an instrument Octopus , which provided efficient isoelectric focusing [7] on complex biological samples. Another continuous free flow device has been demonstrated by Soulet et al. [8]. In this device a pH gradient is created in a flat chamber using carrier ampholytes and a potential gradient perpendicular to the carrier flow direction. The sample is continuously injected and partitioned at the end of the device in discrete fractions.

In another system, called isoelectric split-flow thin (SPLITT) fractionation, no $\mathrm{pH}$ gradient is established, but the separation principle is based on the charge that proteins exhibit depending on their isoelectric point $(p /)$ in buffers of a different $\mathrm{pH}$. A potential is applied to a flow cell using adequate outlet and/or inlet splitters to separate the protein fractions. Two component protein mixtures have been successfully separated [9], but this system exhibits some drawbacks when complex protein samples have to be analyzed and when the $\mathrm{pl}$ of proteins are very close ( $\mathrm{p} /$ differences less than $0.1 \mathrm{pH}$ unit).

Many recycling isoelectric systems are based on the physical separation of compartments with different $\mathrm{pH}$ by means of membranes or screens. Some of them have been reviewed in the literature [10-12]. One of the most common preparative approaches to recycling free-flow 


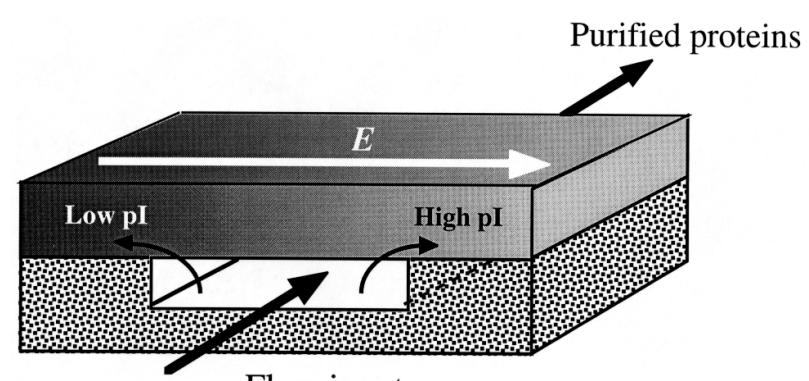

Flow input

Proteins mixture

Figure 1. Schematic diagram of the Off-Gel electrophoretic separation method.

electrophoresis is the Rotofor apparatus, commercialized by Bio-Rad (Hercules, CA, USA). In a tube-like apparatus where compartments are defined by a screening material, the $\mathrm{pH}$ gradient is established using special ampholytes, the so-called Rotolytes . Gravity problems in free-flow electrophoresis are overcome by the rotation of the separation compartments. This device has been successfully applied to the preparative scale. A modification of this approach is the tangential electrophoretic apparatus from Bier [10]. Here, the different compartments are arranged in such a manner that an array of multi-channels is separated from a second array of multichannels slightly displaced through a single screen. An electrical field is applied perpendicularly to the channels, which enables an electrophoretic serpentine pathway through the channels. The $\mathrm{pH}$ in the channels is fixed by carrier ampholytes and recycling is possible with independent inlet and outlet ports at every channel. Finally, Corthals et al. [13] presented a system called Gradiflow (Gradipore, Frensch Forest, Australia), where a screen separates two adjacent flowing solutions and where an electric field in applied perpendicularly to the screen, forcing charged molecules to transfer from one compartment to another one with respect to their charge. By controlling the $\mathrm{pH}$ in the flowing solution with carrier ampholytes, isoelectric focusing separation can be run in this instrument.

In most solution-buffered systems, the analyte is mixed with a running buffer and several strategies of fluid handling are presented to either fractionate or desalt the sample or to work in a nonconvective and/or low water diffusion medium. These isoelectric focusing devices have a major disadvantage in terms of further analysis of compounds. They all contain in the final separated fraction a certain amount of undesired buffering species or ampholytes.

In most immobilized buffering systems such as the 2-D gel, there is another disadvantage, which is the final separation of the fraction trapped in a gel or membrane.
Therefore, Righetti and Faupel $[14,15]$ provided a technique, which is based on isoelectric membranes, but which recovers proteins in carrier ampholyte-free solution. This device can be composed of several compartments separated by immobiline gels stabilized by membranes. The separation of fractions is achieved in such a way that the protein stops migrating in an electrical field in between two immobiline membranes, wherein one membrane establishes a $\mathrm{pH}$ higher than the protein's $\mathrm{pl}$ and the other a $\mathrm{pH}$ lower than it. With this device, impurities in protein extracts with $\Delta \mathrm{p} /$ of only 0.01 could be successfully eliminated.

Similarly, the novel Off-Gel technology presented here enables the extraction of proteins of a given $\mathrm{p} /$ from complex samples, whilst maintaining the proteins in solution without the need of carrier ampholytes or buffers. This system is composed of a chamber where one wall of the chamber is an immobilized $\mathrm{pH}$ gradient gel. If the chamber is thin enough the proteins situated in the solution close to the gel will be buffered by it. By applying an electric field through the chamber, all charged species at this $\mathrm{pH}$ migrate out of the chamber, into the gel. In the solution, only the proteins with an isoelectric point close to the one of the gel in contact with the chamber stays in solution. The advantageous feature of this instrument is that it can work for down-scale volumes, typically in the order of 0.1 to $1 \mathrm{~mL}$.

\section{Materials and methods}

\subsection{Finite element simulation of the electric field distribution}

The Off-Gel device is composed of a flow chamber where one wall consists of an IPG gel in such a way that this IPG gel buffers a thin layer of the solution. From a hydrodynamic viewpoint, this thin layer corresponds to the convection free diffusion layer present next to any solid surface. The direction of the $\mathrm{pH}$ gradient within the gel is perpendicular to the flow direction within the channel as illustrated in Fig. 1. An important aspect to be understood in Off-Gel electrophoresis is the distribution of the electric field above the chemical buffering system. Numerical simulations have been run in order to visualize the field distribution when the chamber presented in Fig. 1 is filled by a solution in contact with the IPG gel. The simulation of potential and the migration current distributions is performed using a commercial finite element software package (Flux-Expert, Simulog Grenoble, Montbonnot St. Martin, France) and operated on a UNIX workstation (Silicon Graphics Indigo 2 Impact 10000, 640 Mb RAM). 
The current lines are calculated by solving Laplace equation (1) in Cartesian coordinates as already described elsewhere [16]:

$\Delta V=0$

\subsection{Separation of eglin $c$ from a mixture of $\mathrm{pl}$ markers}

To demonstrate the principle of Off-Gel electrophoresis, $100 \mu \mathrm{L}$ of a mixture containing $1 \mathrm{mg} N$-acetyl Eglin $c$ (p/ 5.5) and $10 \mu \mathrm{L}$ Biomark (Bio-Rad) synthetic $\mathrm{p} /$ markers, which are low molecular weight amphoteric compounds with strong UV absorbency ( $\mathrm{p} / 5.3,6.4,7.4,8.4$ and 10.4) in $1 \mathrm{~mL}$ water is flowing on an IPG gel $(\mathrm{pH} 4$ to 7, Amersham Pharmacia Biotech, Uppsala, Sweden) under Off-Gel conditions described here after. A $4 \times 4 \mathrm{~cm}^{2}$ piece of gel (IPG 4-7) is cut so that the middle corresponds to the $\mathrm{pH} 5.5$ line (exactly $5.5 \mathrm{~cm}$ from the anodic side of the IPG gel). The Off-Gel chamber has a width of $4 \mathrm{~mm}$, a depth of $0.6 \mathrm{~mm}$ and a length of $4 \mathrm{~cm}$. The piece of gel is then introduced in the Off-Gel device made of Perspex, and reswelled in ultra pure water for $30 \mathrm{~min}$. $100 \mu \mathrm{L}$ of $10 \mathrm{~mm}$ phosphoric acid and $100 \mu \mathrm{L}$ of $10 \mathrm{~mm}$ sodium hydroxide solutions respectively are filled in the anodic and cathodic reservoir of the Off-Gel device. The protein marker mixture $(100 \mu \mathrm{L}$ from the stock solution, as already described) is recycled in a loop at $0.045 \mathrm{~mL} / \mathrm{min}$ using a mini-peristaltic pump with Pharmed tubing (0.63 mm diameter) (Ismatec, Zurich, Switzerland). Fittings are commercially available (DiagnoSwiss, Monthey, Switzerland). After 12 and 60 min of separation, aliquots $(10 \mu \mathrm{L})$ are mixed with $30 \mu \mathrm{L}$ of biolytes (Bio-Rad) and analyzed by CE IEF. Depending on the results, the Off-Gel separation can be stopped or extended. If a high resolution is needed, the circulating mixture can be submitted under other gel conditions ("narrow" IPG gradient pH 5-6, for example). CE IEF conditions: apparatus: Biofocus 3000 from Bio-Rad; capillary: Biocap XL coated $50 \mu \mathrm{m}$ id $\times 375 \mu \mathrm{m}$ od $\times 27 \mathrm{~cm}$; injection time $20 \mathrm{~s}$ at 100 psi; polarity + to -; focus end point $240 \mathrm{~s}$ or $0.3 \mu \mathrm{A}$; focusing voltage $15 \mathrm{kV}$; mobilization voltage $15 \mathrm{kV}$; current limit $100 \mu \mathrm{A}$; detection $280 \mathrm{~nm}$; run time $40 \mathrm{~min}$; range 0.1 AUFS (absorbance units full scale).

\subsection{Protein extraction from $E$. coli}

The starting material was an $E$. coli suspension ( $E$. coli lyophilized cells of strain B -ATCC 11303 / Sigma) stored at $-20^{\circ} \mathrm{C} .250 \mathrm{mg} \mathrm{E}$. coli were diluted in $10 \mathrm{~mL}$ of Rabilloud buffer [17] composed of $7 \mathrm{M}$ urea, $2 \mathrm{M}$ thiourea, $4 \%$ CHAPS and 1\% DTT. All the reagents used for the preparation of this buffer were obtained from Amersham
Pharmacia Biotech. The cell suspension was then disrupted with an ultrasonic probe during 2 min to ensure cell lysis and protein extraction. After centrifugation at $60000 \mathrm{rpm}$ for $30 \mathrm{~min}$, the supernatant was diluted (1:1) in Rabilloud buffer. Protein concentration was approximately $12 \mathrm{mg} / \mathrm{mL}$.

\subsection{Off-Gel purification of $E$. coli extract}

The chemical buffering system was an IPG gel (Amersham Pharmacia Biotech) with $\mathrm{pH} 4-7$. A $4 \times 4 \mathrm{~cm}^{2}$ piece of gel was cut so that the middle corresponded to the $\mathrm{pH} 4.7$ line. The piece of gel was then introduced in the device and reswelled in Rabilloud buffer overnight at room temperature. $100 \mu \mathrm{L}$ of $10 \mathrm{~mm}$ phosphoric acid and $10 \mu \mathrm{L}$ of $10 \mathrm{~mm}$ hydroxide solutions respectively were filled in the anodic and cathodic reservoir of the device. The sample was recirculated for $3 \mathrm{~h}$ in a loop using a mini-peristaltic pump (Ismatec) with a flow-rate of $80 \mu \mathrm{L} /$ min. The starting electrical conditions were $500 \mathrm{~V}$ for $30 \mathrm{~min}$ followed by $1000 \mathrm{~V}$ for $3 \mathrm{~h}$.

\subsection{Mini 2-D analysis of $E$. coli extract}

The E. coli extract prior and after the Off-Gel was analyzed by 2-D gel in order to visualize the performance of the separation. For the first dimension (IEF), linear $7 \mathrm{~cm}$ immobilized $\mathrm{pH}$ gradients (3-10) strips were rehydrated with the samples according to the procedures described by the supplier (Amersham Pharmacia Biotech). IEF was performed in a Pharmacia Multiphore with an immobiline DryStrip kit. The starting electrical conditions were $300 \mathrm{~V}$ for $1 \mathrm{~h}$, followed by $500 \mathrm{~V}$ for an additional hour and $3500 \mathrm{~V}$ for a final $2 \mathrm{~h}$.

The second dimension (molecular weight separation) was performed using mini-gels (Tris-glycine 4-20\%; Novex, San Diego, CA, USA) on which the IEF strips were placed and fixed with agarose. The separation was run using a Xcell SureLockTM Mini-Cell (Novex) in Tris glycine SDS buffer (Bio-Rad). A voltage of $125 \mathrm{~V}$ was applied and the separation was completed in $2 \mathrm{~h}$. The staining was performed using a standard technique with Coomassie blue (Bio-Rad).

\section{Results and discussion}

\subsection{Numerical simulation of the electric field distribution in the Off-Gel device}

The Off-Gel device shown in Fig. 1 presents the flow chamber closed by an IPG gel. In order to illustrate the field distribution in the thin layer of solution in contact 


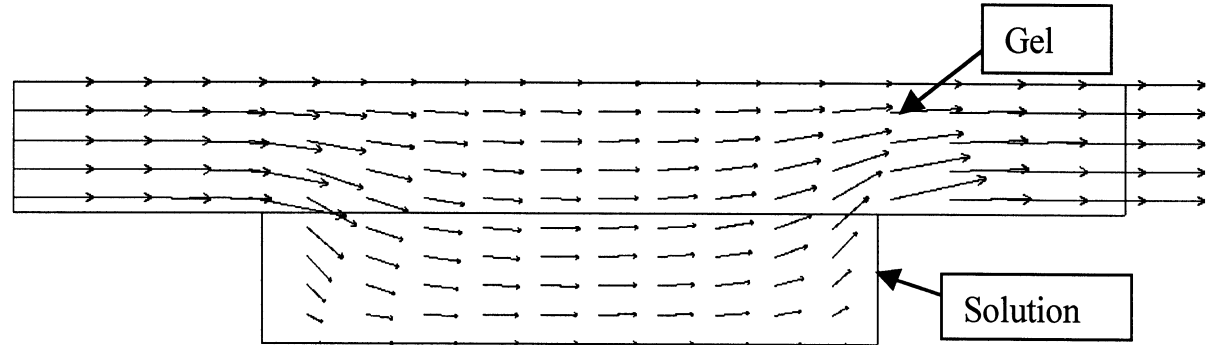

Figure 2. Current line distribution in a cross section of the Off-Gel apparatus. The length of the arrows is proportional to the current intensity. with the gel, a simulation experiment has been run and the resulting lines of current are presented in Fig. 2. When an electric field is applied along the immobilized $\mathrm{pH}$ gradient, some lines of current enter the flow channel and thereby induce the migration of charged species by electrophoresis. The proteins in the thin layer of solution close to the IPG gel are charged according to their isoelectric point and according to the $\mathrm{pH}$ imposed by the buffering capacity of the gel. The electric field in this buffered thin layer therefore separates the proteins, as if they were in the gel itself. The positively charged proteins migrate to the cathode and penetrate the gel following the lines of current, whereas the negatively charged ones penetrate the gel to migrate to the anode as shown in Fig. 1. Of course, others ions will also migrate with the electric field and water dragging into the gel is possible depending upon the current density used. Neutral species, which are not affected by the electric field, remain in the solution, among them the proteins with a $\mathrm{pl}$ equal to the $\mathrm{pH}$ imposed by the IPG gel above the flowing solution.

\subsection{Off-Gel purification of Eglin c from $\mathrm{p} /$ marker}

The Off-Gel principle is only operational if the electrical field enters the flow chamber in order to induce the migration of charged species in the flow solution. Simulation results also indicate that the lower the conductivity of the flowing solution compared to that of the IPG gel, the larger the electric field, and therefore the more efficient the separation. Therefore, to enhance the field strength in the thin layer of solution the next experiment will be performed in pure water with highly soluble proteins or $\mathrm{p} /$ markers.

Figure 3 shows the separation of the protein Eglin $c$ from a mixture of $\mathrm{pl}$ markers. It can clearly be observed that despite the low current density used, most of the markers with high $\mathrm{pl}$ were eliminated from the solution within 12 min of recirculation of the solution in a loop, and that a complete purification could be achieved within one hour. The $\mathrm{pl}$ resolution of this experiment is less than $0.1 \mathrm{pH}$ unit. It is also possible to use ultra-zoom gels to further define the $\mathrm{p} /$ range of purified proteins.
The present method of purification as described here shows some advantages over solution buffered systems. The Off-Gel electrophoretic separation allows the proteins to be recovered in solution, but the addition of carrier ampholytes is not required as it is the case in other continuous free-flow devices, such as free flow electrophoresis [7], Gradiflow [13], isoelectric split-flow thin

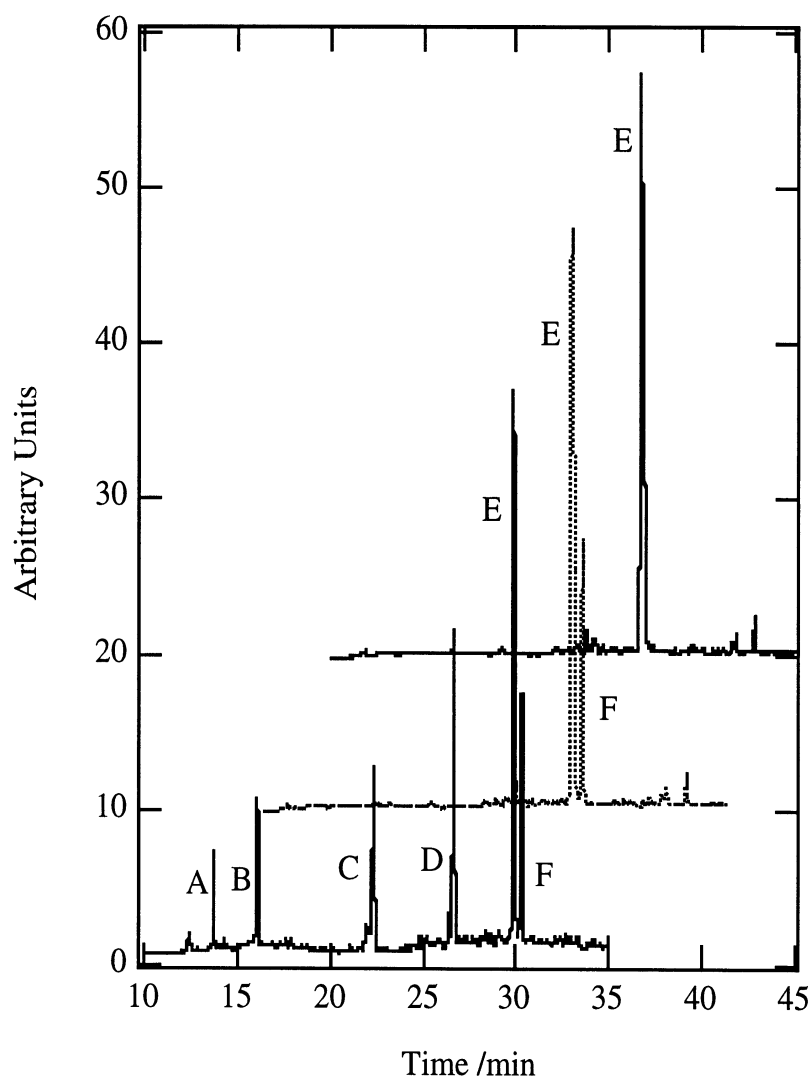

Figure 3. Bottom curve: Electropherogram of the mixture of $\mathrm{p} /$ markers + Eglin $c:$ : (a) $\mathrm{p} /=10.4$, (b) $\mathrm{p} /=8.4$, (c) $\mathrm{p} l=7.4$, (d) $\mathrm{p} l=6.4$, (e) Eglin $c \mathrm{p} l=5.5$ and (f) $\mathrm{p} l=5.3$. Middle curve: After $12 \mathrm{~min}$ of electrophoresis at $500 \mathrm{~V}$, purification is achieved from the markers of higher $\mathrm{pl}$, which are found in the catholyte compartment (data not shown). Top curve: Complete purification of recombinant Eglin c, p/ 5.5, after one hour. 
a

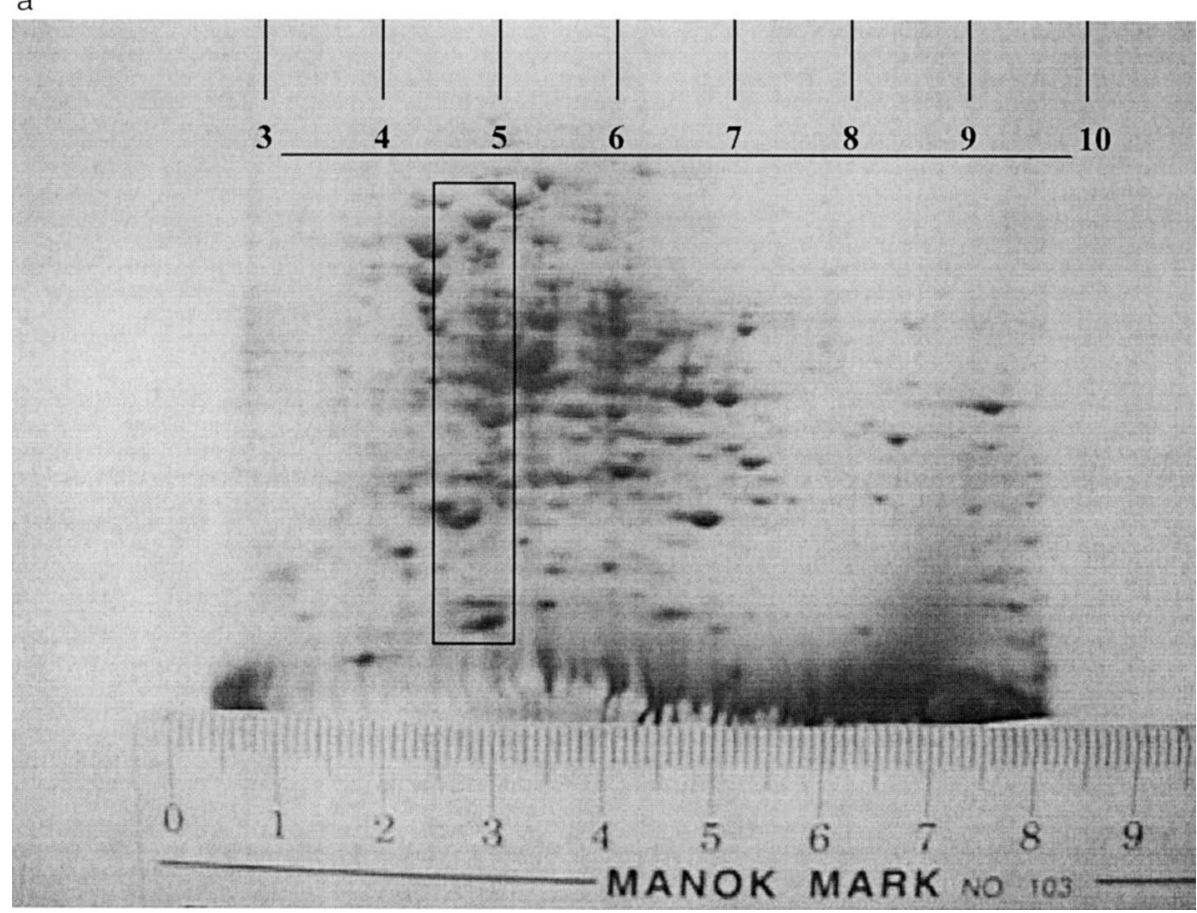

b

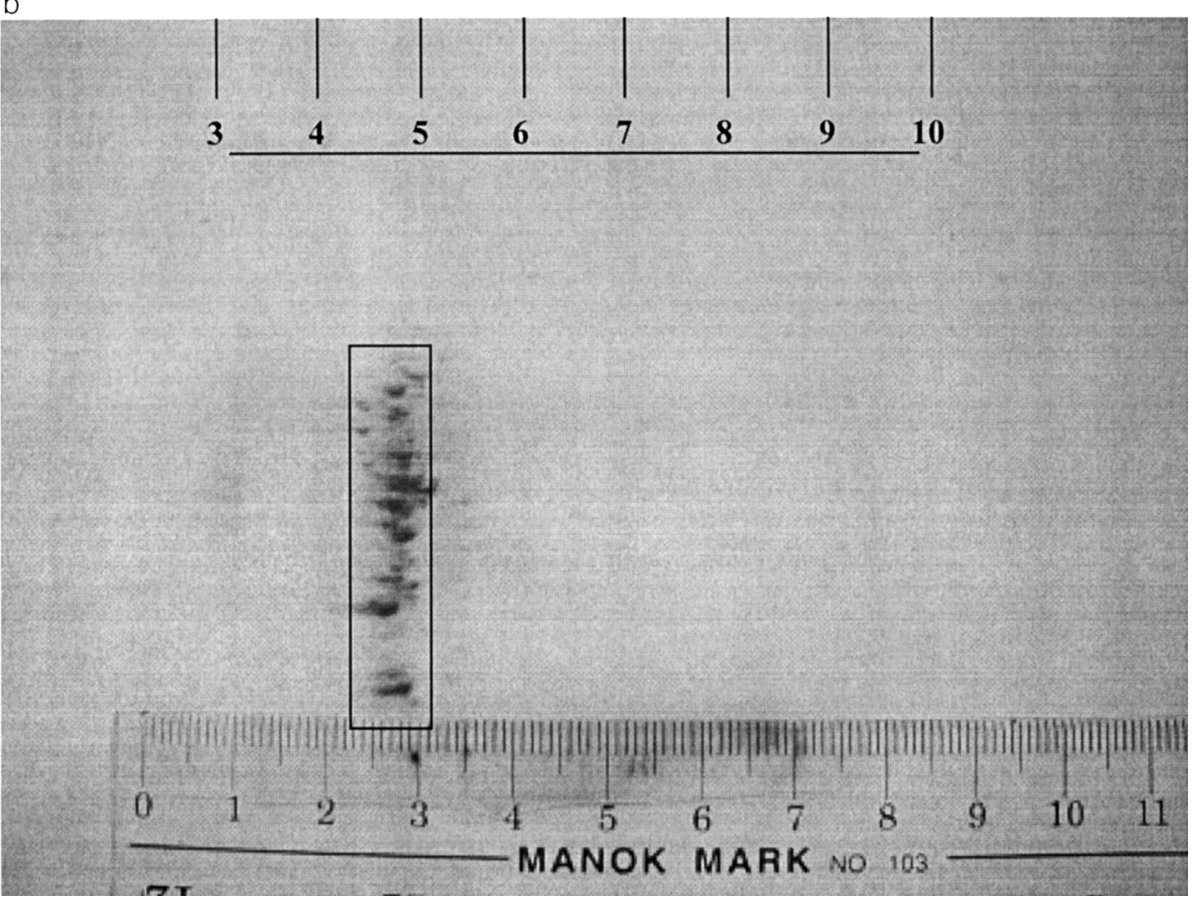

Figure 4. (a) Mini 2-D gel image of an $E$. coli extract separated between $\mathrm{pH} 3$ to 10; (b) Mini 2-D gel image of an $E$. coli extract after Off-Gel purification between $\mathrm{pH} 4.4$ to 5 in a $\mathrm{pH}$ 3-10 gradient.
(SPLITT) fractionation [9] or in the tangential electrophoretic apparatus as described by Bier [10]. When compared to segmented IEF as presented by Faupel et al. [14] or more recently by Righetti et al. [5], the major advantage of the Off-Gel electrophoresis is that the field is applied tangentially to the gel rather than across the gel mem- brane, thereby reducing the risk of membrane blockage by precipitation. In the present approach, the system is self-buffered and the proteins are driven by the tangential electrical field with respect to their charge. As in any IEF method, solubility problems may arise during the transfer from the liquid phase (the sample) to the gel phase. Such 
a phenomenon is of course more prominent when high amounts of proteins are in contact with the IEF gel. The use of chaotropes such as thiourea, or detergents such as CHAPS, or a combination of chaotropes and detergents [17], can help to keep proteins in solution as shown in the next experiment.

\subsection{Separation of E. coli extract}

In order to demonstrate the use of the Off-Gel technology in a complex biological mixture, an E.coli extract has been separated where $\mathrm{pH} 4.5$ to 4.9 is in contact with the $4 \mathrm{~mm}$ broad Off-Gel chamber. Prior to separation the extract has been analysed by mini 2-D gel electrophoresis between $\mathrm{pH} 3$ and 10 as presented in Fig. 4a. The pattern of the $E$. coli proteins can be recognised even if the 2-D gel is a low resolution one.

After dialysis of the sample in order to decrease the salt content, the protein mixture was applied to the Off-Gel device at $\mathrm{pH} 4.5$ to 4.9 and separated with respect to the above mentioned protocol. After $3 \mathrm{~h}$ the sample has also been analysed by mini 2-D gel and the resulting protein content can be seen on Fig. $4 \mathrm{~b}$. A fraction of protein of a $\mathrm{p} /=4.7+/-0.3$ can be obtained with a relatively good separation efficiency. It should be remembered that this experiment has been conducted with a low resolution gel $(1 \mathrm{pH} \mathrm{U} / \mathrm{cm})$ and that the contact of the gel with the OffGel chamber is of $4 \mathrm{~mm}(0.4 \mathrm{pH}$ unit). This experiment demonstrates that the Off-Gel electrophoresis is applicable to complex biological sample,such as $E$. coli extract. Further experiments, simulation and redesign of the OffGel cell are also planned to push forward the technology in order to know its real potential in terms of buffering capacity, rapidity, multiplexing and resolution.

\section{Concluding remarks}

The Off-Gel methodology presented here can be used to purify proteins within a certain $\mathrm{p} /$ range, which can be at least as narrow as $0.1 \mathrm{pH}$ unit. The proteins are kept in the solution and are ready for further analyses such as 2-D gel, microarray, digestion, crystallization or mass spectrometric analyses. Further work will be conducted in order to analyze quantitatively the losses of proteins inside the Off-Gel device as well as its buffering capacity in extreme experimental conditions.

Received May 21, 2001

\section{References}

[1] Pandey, A, Mann, M., Nature 2000, 405, 837-846.

[2] Wilkins, M. R, Williams, K. L., Apple, R. D., Hochstrasser, D. F. (Eds.), Proteome Research: New Frontiers in Functional Genomics, Springer, Berlin 1997.

[3] http:/www.expasy.ch

[4] Lueking, A., Horn, M., Eickhoff, H., Lehrach, H., Walter, G., Anal. Biochem. 1999, 270, 103-111.

[5] Righetti, P. G., Castagna, A., Herbert, B., Anal. Chem. 2001, 73, 320a-326a.

[6] Macounova, K., Cabrera, C. R., Holl, M. R., Yager, P., Anal. Chem. 2000, 72, 3745-3751.

[7] Burggraf, D., Weber, G., Lottspeich, F., Electrophoresis 1995, 16, 1010-1015.

[8] Soulet, N., Roux-de Balmann, U., Sanchez, V., Electrophoresis 1998, 19, 1294-1299.

[9] Fuh, C. B., Giddings, J. C., Sep. Sci. Technol. 1997, 32, 2945-2967.

[10] Bier, M., Electrophoresis 1998, 19, 1057-1063.

[11] Krivankova, L., Bocek, P., Electrophoresis 1998, 19,10641074.

[12] Baygents, J. C., Schwarz, B. C. E., Deshmukh, R. R., Bier, M., J. Chromatogr. A, 1997, 779, 165-183.

[13] Corthals, G. L., Molloy, M. P., Herbert, R. B., Williams, K. L., Zooley, A. A., Electrophoresis 1997, 75, 317-323.

[14] Faupel, M., Barzaghi, B., Gelfi, C., Righetti, P. G., J. Biochem. Biophys. Methods, 1987, 15, 147-162.

[15] Righetti, P. G., Wenisch, E., Faupel, M., J. of Chromatogr., 1989, 475, 293-309.

[16] Belmont, C., Girault, H. H., J. Appl. Electrochem. 1994, 24,475 .

[17] Rabilloud, T., Electrophoresis 1996, 77, 813-829. 